Schlotheuber, Eva, Seibert, Hubertus, Böhmen und das Deutsche Reich, Ideen- und Kulturtransfer im Vergleich (13.-16. Jahrhundert)

\title{
Éloïse Adde
}

\section{OpenEdition}

Édition électronique

URL : http://journals.openedition.org/ifha/2131

DOI : 10.4000/ifha.2131

ISSN : 2198-8943

Éditeur

IFRA - Institut franco-allemand (sciences historiques et sociales)

Référence électronique

Éloïse Adde, «Schlotheuber, Eva, Seibert, Hubertus, Böhmen und das Deutsche Reich, Ideen- und Kulturtransfer im Vergleich (13.-16. Jahrhundert)», Revue de I'IFHA [En ligne], Date de recension, mis en ligne le 01 janvier 2010, consulté le 22 septembre 2020. URL : http://journals.openedition.org/ifha/ 2131 ; DOI : https://doi.org/10.4000/ifha.2131

Ce document a été généré automatiquement le 22 septembre 2020.

(C)IFHA 


\title{
Schlotheuber, Eva, Seibert, Hubertus, Böhmen und das Deutsche Reich, Ideen- und Kulturtransfer im Vergleich (13.-16. Jahrhundert)
}

\author{
Éloïse Adde
}

1 Résultat du colloque tenu à Munich du 10 au 12 septembre 2007, cet ouvrage se propose de réfléchir sur les développements historico-politiques et culturels respectivement de la Bohême et du Saint-Empire germanique et sur les thèmes de voisinage et cohabitation et d'entrelacement des développements respectifs des deux espaces de la fin du Moyen Âge aux débuts des Temps modernes. Tout en multipliant les angles d'approches, ce colloque pose la question non seulement des formes et des voies prises par les transferts culturels et scientifiques, mais encore des intermédiaires et des modes de communication qui les assurèrent. Reprenant le concept de " transfert culturel " comme processus d'échange réciproque entre au moins deux cultures nationales, fondé par Michel Espagne et Michael Werner dans les années 1980, les interventions successives réfléchissent aussi aux différentes strates mises à l'œuvre dans l'assimilation de biens culturels étrangers et à la notion de « Mischprodukt » (M. Espagne), de produit hybride, résultat de la double influence de la culture cible et de la culture source. Pour affiner la compréhension de cette problématique, le colloque intègre aussi les transferts culturels entre la France et la Bohême et insiste sur la particularité des pays tchèques qui sont à la fois une région de l'Empire (G. Vogeler) tout en veillant à bien se distinguer du modèle allemand.

2 Ce colloque se veut dans la continuation du colloque d'Erlangen « Kulturtransfer. Perspektiven eines Forschungsansatzes " (21-23 juin 2007) qui s'était employé à identifier les processus et les conditions prévalant dans les importations et les exportations culturelles, tout en déplaçant la perspective et en mettant l'accent sur les transformations et les rejets que ces échanges impliquaient et en approfondissant la thématique du transfert culturel dans toute sa mesure (échange, médiation, 
adaptation). Trois axes ressortent nettement des travaux communiqués : la notion de tournant dans le contexte de changements dynastiques successifs et de l'émancipation de la haute noblesse ; la réception par la culture cible et la transformation $\mathrm{du}$ " bien » reçu ; la méthode de l'« histoire croisée » dans la mesure où le transfert induit au moins deux espaces différents avec leur histoire respective.

Les liens entretenus entre la France et la Bohême occupent une place non-négligeable, rappelant l'importance du modèle français, en particulier pour la mise en scène du pouvoir royal et la propagande étatique, sous la dynastie des Luxembourg. B. Carqué et R. Nemec s'intéressent au rôle de l'architecture dans le projet politique des Luxembourg et à la double intention de conservation de l'héritage tchèque přemyslide et d'innovation liée aux importations françaises. Les réflexions de J. Royt sur le rôle de mécène de l'évêque Jean IV de Dražice l'amène également à privilégier les échanges avec la France, l'évêque de Prague ayant ramené de ses voyages en Avignon non seulement un intérêt marqué pour l'art français et italien, mais également de nombreuses œuvres.

Les échanges tchéco-allemands introduisent une donnée supplémentaire : l'intégration des modèles du voisin n'est jamais neutre et s'effectue tout en veillant à bien se différencier par rapport à lui dans un contexte de concurrence, voire de conflit. C'est ce que soulignent les réflexions d'A. Hindin sur le rôle de l'identité ethnique dans la production et la réception des œuvres d'arts en Europe centrale, en s'appuyant sur le cas particulier de la construction d'édifices religieux allemands et tchèques en Bohême et en Moravie : l'architecture religieuse tchèque (1150-1420) s'affirme de manière totalement antinomique par rapport au modèle allemand dans le but d'affirmer une identité tchèque qui se veut résolument autre. J. Roháček soulève également la question du peuplement allemand en Bohême à travers son étude des inscriptions en allemand dans les pays tchèques du XIIIe au XVIe siècle. Constatant l'indigence de ce legs qui ne rend pas compte de la présence allemande massive et durable, il met aussi le doigt sur les problèmes ethniques et d'affirmation nationale des Tchèques par rapport aux Allemands, qu'il situe déjà bien avant le mouvement hussite.

Pour ce qui est des modalités des transferts et des intermédiaires, L. Mračková met en valeur le rôle déterminant du Saint-Empire, véritable passeur entre l'Europe occidentale et l'Europe centrale, à travers l'exemple de la diffusion vers la Bohême de la polyphonie franco-flamande à partir de la cour impériale de Frédéric III. M. Hamsíková s'intéresse plutôt à l'acculturation d'un modèle étranger et à l'influence de Lucas Cranach le Vieux sur la peinture tchèque et morave de la première moitié du XVIe siècle.

6 U. Tresp aborde les stratégies exploitées par une famille récente et encore peu affirmée, les Schlik de la région frontalière de Cheb, qui tire son épingle du jeu à la fin du Xve siècle du fait de son inscription dans les deux cultures tchèque et allemande, qui lui permet une fructueuse double activité tant au sein du royaume de Bohême que du Saint-Empire germanique.

Plus concentrées sur la Bohême, les interventions de P. Soukup, J. Záruba-Pfeffermann et $\mathrm{F}$. Záruba étudient la circulation des idées à l'intérieur de l'espace tchèque. P. Soukup identifie le sermon comme un objet de commerce religieux ; il montre comment les prédicateurs hussites s'approprièrent les techniques littéraires de l'exégèse biblique et les structures de l'argumentation scholastique propres à toute l'Europe chrétienne pour ébaucher sur cette base leur propre système, qui leur valut de s'imposer par la 
suite au concile de Bâle. J. Záruba-Pfeffermann nous introduit dans l'église de Slavětín, dans la région de Louny en Bohême occidentale, dont les murs sont recouverts de l'une des plus riches fresques médiévales de Bohême et nous donne un bel exemple de mise en scène de la cour de Venceslas IV en dehors de Prague dans son association aux nobles locaux. F. Záruba reprend la même thématique à travers la politique de construction de châteaux menée essentiellement dans les années 1380 par Venceslas IV.

8 Par la diversité des sujets abordés et des approches, cet ouvrage rend bien compte des différentes modalités d'appropriation et d'adaptation, ou encore de rejet, des biens culturels étrangers en Bohême. On peut néanmoins déplorer que les articles ne répondent pas à toutes les questions soulevées en introduction, le Saint-Empire étant compris exclusivement comme une culture source. En outre, les mécanismes d'assimilation de la Bohême et du Saint-Empire ne sont jamais comparés contrairement à ce qui avait été annoncé. Le tout reste cependant extrêmement riche et permet de rendre accessibles dans une langue plus courante les recherches conduites par la nouvelle génération de chercheurs tchèques.

Éloïse Adde (CEFRES, Prague) 